\title{
Standardization of laboratory and lipid profile evaluation: A call for action with a special focus in 2016 ESC/EAS dyslipidaemia guidelines - Full report ${ }^{\text {光 }}$
}

\author{
Pedro Marques da Silva ${ }^{\text {a, }}$, J. Sequeira Duarte ${ }^{b}$, Pedro von Hafe ${ }^{c}$, Victor Gil ${ }^{\text {, }}$, \\ Jorge Nunes de Oliveira ${ }^{e}$, Germano de Sousa ${ }^{f}$ \\ ${ }^{\text {a }}$ Coordinator of the Cardiovascular Risk and Prevention Group of the Portuguese Internal Medicine Society, Arterial Investigation Unit, Medicine \\ Department, Medicina 4, Hospital de Santa Marta - Centro Hospitalar de Lisboa Central, EPE, Lisboa, Portugal \\ ${ }^{\mathrm{b}}$ General Secretary of the Portuguese Atherosclerosis Society, Endocrinology Department - Hospital de Egas Moniz, Centro Hospitalar de Lisboa Ocidental, \\ EPE, Lisboa, Portugal \\ ${ }^{\mathrm{c}}$ Member of the Board of the Cardiovascular Risk and Prevention Group of the Portuguese Internal Medicine Society, Internal Medicine Department, Centro \\ Hospitalar São João, Porto, Portugal \\ ${ }^{\mathrm{d}}$ Elect President of the Portuguese Society of Cardiology, Cardiovascular Unity, Hospital Lusíadas Lisboa, Lisboa, Portugal \\ e President of the Portuguese Association of Clinical Chemistry, Board of the Portuguese Society of Laboratory Medicine, Clinical analysis laboratory "Prof. \\ Doutor Joaquim J, Nunes de Oliveira, Lda", Póvoa do Varzim, Portugal \\ f re. Germano de Sousa Group - Centro de Medicina Laboratorial, Pólo Tecnológico de Lisboa, Portugal
}

\section{Keywords:}

Dyslipidaemia

Clinical laboratory reports

Standardization

Cardiovascular risk

Lipid goals

\begin{abstract}
A B S T R A C T
Even with the improvement in lifestyle interventions, a better control of cardiovascular (CV) risk factors, and improvements in CV outcomes, cardiovascular disease (CVD) still persists as the leading cause of morbidity and mortality in Portugal and Europe. Atherogenic dyslipidaemias, namely hypercholesterolaemia, have a crucial and causal role in the development of atherosclerotic CVD. The clinical approach of a patient with dyslipidaemia involves a watchful diagnosis, sustained in lipid and lipoprotein laboratory procedures, which must be harmonized and standardized. Standardization of lipid test results and reports, incorporating the total CV risk and the respective target and goals of treatment approach, guarantees that clinical guidelines and good clinical practices are followed and respected, increasing the reliability of lipid disorders screening, producing more accurate diagnoses and CV risk stratification, and improving the CV prevention and the achievement the desirable treatment goals.
\end{abstract}

(C) 2018 Published by Elsevier B.V.

\section{Background and rationale}

Even with the promotion of healthy life behaviours, the incremental control in cardiovascular (CV) risk factors, and the improvements in $\mathrm{CV}$ outcomes, cardiovascular disease (CVD) continues to be the leading cause of morbidity and mortality in Portugal and Europe [1-3]. Annually, CVD causes the death of more

\footnotetext{
A consensus endorsed by the Cardiovascular Risk and Prevention Group of the Portuguese Internal Medicine Society, the Portuguese Atherosclerosis Society, the Portuguese Society of Cardiology, the Portuguese Society of Laboratory Medicine, and the Portuguese Association of Clinical Chemistry. Publication of this supplement was supported by the European Atherosclerosis Society.

* Corresponding author. Arterial Investigation Unit, Medicina 4, Hospital de Santa Marta - CHLC, EPE, Lisboa Rua de Santa Marta, 50, 1169-024, Lisboa, Portugal.

E-mail address: pedro.silva@chlc.min-saude.pt (P.M. da Silva).
}

than 4 million people in Europe [4]. In Portugal, in 2014, diseases of the circulatory system and malignant neoplasms were the 2 main underlying causes of death, accounting for $55.6 \%$ of all deaths. Despite the progressive trend of decreasing in that year, death was mainly originated by diseases of the circulatory system $(30.7 \%$ of the total deaths), with a startling increase of $2.4 \%$ in comparison with 2013. Cerebrovascular diseases and ischaemic heart disease stood out in the group of deaths caused by diseases of the circulatory system [1]. The number of deaths from stroke in 2013 was 11.751 , corresponding to a mortality rate of 54.6 per 100 thousand inhabitants (in people $>65$ years, this number grows exponentially reaching 630.2 per 100000 inhabitants). Ischemic cardiac disease causes 6526 deaths (a standardized mortality per 100000 inhabitants of 32.9). By comparison, in the same period, deaths from myocardial infarction (MI), affected 4.292 individuals (standardized mortality rate of 22.2) [2]. 
Atherogenic dyslipidaemias, namely hypercholesterolaemia, have a crucial and causal role in the development of atherosclerotic CVD (ASCVD) [5], nowadays, no longer questioned. Increased plasma levels of cholesterol-rich apolipoprotein-B (apoB)-containing lipoproteins - especially low-density lipoprotein cholesterol (LDL-C) - are causatively related with ASCVD [5,6]. The role of triglyceride-rich lipoproteins (TGRL) is under active investigation. Remnant lipoproteins [total cholesterol - (LDL-C + HDL-C)] have been identified in Mendelian randomization studies, similar to LDL$\mathrm{C}$, as pro-atherogenic lipoproteins [7]. In face of the knowledge we have acquired over the years on the pathogenesis of atherosclerosis, it is tempting to reclassify the recognized ASCVD risk factors into causative and exacerbating, and consider the other as "mere" bystander phenomena, so that, unlike onlooker elements, causal and aggravating factors must be elected targets for therapy (6) (Table 1).

The prevalence of dyslipidaemia in Portugal has been studied in various regional and national epidemiological studies for the last decades [8-12]. In 2010, the prevalence of hypercholesterolaemia was estimated in $55.5 \%$ of the population aged $>18$ years $(56.7 \%$ male and $54.5 \%$ female). A recent study evaluated the costs and the burden of hypercholesterolaemia in Portugal [13], assuming that, in 2010,1689 deaths can be attributed to hypercholesterolaemia (1.6\% of the total deaths in Portugal in 2010). The DALYs (disability adjusted life years) resulting from disability and premature deaths caused by hypercholesterolaemia were 12,174 (481 from acute MI, 235 from other ischemic heart disease and 974 from ischemic stroke). The estimated direct cost attributable to hypercholesterolaemia, corresponding to 2013 prices, was $€ 320$ millions ( $€ 32$ millions for in-patient care and $€ 288$ millions for ambulatory care). Indirect costs generated by disability attributable to hypercholesterolemia add up to $€ 198$ millions. Therefore, the overall costs of disease are estimated at $€ 518$ millions, $\approx 0.3 \%$ of the Portuguese GDP (gross domestic product).

The clinical approach of a patient with dyslipidaemia (in primary or secondary prevention) requires an attentive diagnosis, sustained by lipid and lipoprotein laboratory measurement [14]. With a scarce (but very appealing) clinical symptomatology and semiology, the diagnosis is based on the understanding of lipoprotein metabolism (which influences the choice of the treatment proposed), on the laboratory confirmation of dyslipidaemia, the exclusion of a secondary cause (which can coexist, influence or modulate the expression of a primary dyslipidaemia), and the evaluation of global CV risk; and the decision of treat, discussing and analyzing the most appropriate strategy, using the best scientific evidence, compared with clinical experience and patient's expectations.

An adequate screening, prevention, diagnosis, monitoring and treatment, combined with an accurate and standardized laboratory diagnosis, are essential to the management of dyslipidaemias and CVD prevention in clinical practice [4,5]. Several international guidelines and recommendations have been published, and are regularly updated, intending to promote the prevention and treatment of ASCVD. In Europe, in 2016, the European Atherosclerosis Society (EAS) and the European Society of Cardiology published the "2016 ESC/EAS guidelines for the management of dyslipidaemias" [4], complementing and individualizing the "2016 European guidelines on cardiovascular disease prevention in clinical practice" [5]. In Portugal, 3 specific standards of good clinical practice (GCP) made available by the Directorate General of Health (DGS) on this same topic [15-17]. These should be sources of guidance and instruments to support clinical decision in the $\mathrm{Na}-$ tional Health Service and to promote the development of excellence in health care and their evaluation in the hospital networks, health centres, family health units and continuous care.

In this paper, a panel of experts of clinical pathology and laboratorial medicine, lipidology, cardiology, internal medicine and endocrinology intend to gather the evaluation of lipid profile in Portugal, with a special focus on treatment targets and goals, acknowledging that lipid goals are part of the CV risk reduction strategy and that they are defined according to the individual global $\mathrm{CV}$ risk stratification. We also want to underline some other lipid

Table 1

Reclassification proposal of ASCVD risk factors (from Borén \& Williams, 2016).

\begin{tabular}{|c|c|}
\hline ASCVD risk & Evidence from human RCTs or MRS \\
\hline \multicolumn{2}{|l|}{ Causal or causative risk factor } \\
\hline $\begin{array}{l}\text { - Elevated plasma LDL-C (and other } \\
\text { apoB-LP) }\end{array}$ & $\begin{array}{l}\text { LDL-C proven in RCTs with statins (and other LDL-C lowering therapies) and in MRS } \\
\text { Other apoB-LP proven in MRS (and in post-hoc analysis from RCTs) }\end{array}$ \\
\hline \multicolumn{2}{|l|}{ Exacerbating risk factor } \\
\hline \multirow[t]{2}{*}{ - Male sex (age) } & Lifetime exposition to an atherogenic vascular ambient \\
\hline & Likewise for elderly men, many of whom no longer develop clinically significant ASCVD \\
\hline - Tobacco smoking & Lifetime low plasma LDL-C levels from genetics or unusual lifestyles reduce the CV risk in active smokers \\
\hline \multirow[t]{2}{*}{ - Hypertension } & $\begin{array}{l}\text { Likewise for hypertension (but extreme hypertension still causes other health problems); subclinical target organ damage (e.g. } \\
\text { vascular remodelling) are not directly related with dyslipidaemia }\end{array}$ \\
\hline & The benefit of adding a statin to antihypertensive treatment is well established and supported by RCTs \\
\hline \multirow[t]{2}{*}{ - Diabetes mellitus } & Likewise for diabetes: lifetime low plasma LDL-C levels protect diabetic patients for the ASCVD events \\
\hline & $\begin{array}{l}\text { Lipid lowering is vital to lower CV risk in type } 2 \text { and type } 1 \mathrm{DM} \text {. All patients }>40 \text { years and selected younger patients at elevated } \\
\text { risk are recommended for statin therapy }\end{array}$ \\
\hline - Elevated glycaemia per se & $\begin{array}{l}\text { Modest genetic elevations in plasma glucose related with ASCVD in MRS (... but in patients with diabetic dyslipidaemia and } \\
\text { increase levels of apoB-LP) }\end{array}$ \\
\hline \multirow[t]{3}{*}{ - Low plasma HDL-C } & Possible an exacerbating factor, but could be a bystander phenomena ... \\
\hline & No proved benefit of raising HDL-C levels in RCTs \\
\hline & Causative role of HDL-C questioned in MRS \\
\hline \multicolumn{2}{|l|}{ Bystander phenomena or risk factor } \\
\hline - Elevated plasma homocysteine & Disproven in RCTs to lower plasma homocysteine levels (with a "fire and forget" strategy ...) \\
\hline \multirow{2}{*}{$\begin{array}{l}\text { - Chlamydia pneumonia infection; } \\
\text { periodontal disease }\end{array}$} & Disproven in RCTs with antibiotics \\
\hline & Interaction with low-grade chronic inflammation \\
\hline \multirow[t]{2}{*}{ - Elevated C-reactive protein } & Disproven in MRS \\
\hline & Consistency across prospective studies as a low-grade inflammatory RF, but the contribution to the CV risk assessment is small \\
\hline \multirow[t]{2}{*}{ - Oxidized LDL } & Disproven in RCTs with antioxidant supplements \\
\hline & Many components of the heart-healthy lifestyle (e.g. exercise, dietary PUFA or moderate alcohol ingestion) are pro-oxidant \\
\hline
\end{tabular}

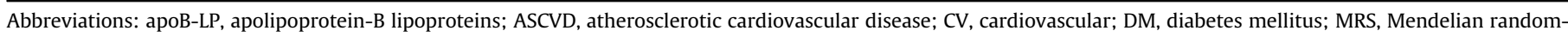
ization studies; RCTs, randomized controlled trials. 
(and non-lipid) biomarkers [e.g. apolipoproteins, non-HDL cholesterol (nHDL-C), lipoprotein (a) (Lp[a]), high-sensitivity C-reactive protein (hs-CRP)], but, on the essentials and in particular, looking for the standardization and the harmonization in the report of lipid test results.

To achieve consensus, the group debated during a live meeting and via the internet. One initial draft was prepared by a designated member and distributed to obtain the opinion of all the other members. The paper is, therefore, the result of a consensusbuilding process by a group of experts that is not necessarily representative of all Portuguese physicians. Nevertheless, all the members are deeply involved in CVD prevention and 2 members work in clinical laboratory procedures and reports. All the authors are members of the main national scientific societies, being frequently called upon to provide recommendations for general practitioners and specialists in CV and laboratory medicine, and all have contributed to the paper review according to their area of expertise. A final document was accomplished and endorsed by the initial proposed Scientific Societies. The harmonization of the lipid profile assessment and reporting can be of great value for clinical analysis laboratories and to provide medical practitioners with the ability to optimize therapy according to each patient's CV risk. This proposal reflects the more recent European guidelines on CVD prevention [5] and on the management of dyslipidaemias [4].

\section{Lipid and lipoprotein analyses}

In addition to a careful clinical history and physical examination, laboratory tests are very important to diagnose dyslipidaemia and to rule out its secondary causes. Therefore, in clinical practice, the estimation of total CV risk, and in particular the ultimate dyslipidaemia diagnosis, entails the accurate and reasonable appreciation -- of laboratory data.

Lipid and lipoprotein concentrations have been measured and described in several ways. Some of these measurements are not easily applied for screening or routine clinical purposes. The cholesterol composition of each lipoprotein class is similar among individuals. Thus, lipoprotein cholesterol is commonly used to evaluate lipoprotein concentration, and these values have been used in the majority of CV risk population studies of, with documented predictive value.

When we are facing a lipid analysis, several issues must be considered. The validation of a lipid measurement must take into account the always present possible sources of variation, which can influence more or less significantly, the quantification and interpretation of results. The more complicated the analytic procedures, the greater the variability of the analyses. As an example, the measurement of plasma lipoproteins requires 2 steps, the partition of the lipoprotein classes and the quantification of the different classes, and both of these steps can contribute to the variability and to possible errors in the measurements.

In addition to analytic sources of error, significant pre-analytic variables may affect measured lipid and lipoprotein levels. We must remember that plasma lipid and lipoprotein measurements are nothing more than laboratorial echo, mirror of a physiological and complex lipoprotein metabolism, which is subjected to different environmental, biological, seasonal, postural and genetic variations. Plasma lipoprotein concentrations can change considerably as a result of normal physiologic variation (Table 2). There is a considerable intra-individual variation in plasma lipids and lipoproteins. Variations of $5-10 \%$ for total cholesterol (TC) and $>20 \%$ for triglycerides (TGs) have been described [4], especially in patients with hypertriglyceridaemia (HTG).

Laboratory measurements provide only part of the reality, the required information to diagnose a dyslipidaemia. Fasting deserves
Table 2

Physiologic variation of plasma lipids, lipoproteins, and apolipoproteins (from Borén \& Williams, 2016)

\begin{tabular}{lll}
\hline Component & CVP (\%) & $\begin{array}{l}\text { CVP (\%) According the National } \\
\text { Cholesterol Education Program 1995 } \\
\text { Working Group on Lipid Measurement }\end{array}$ \\
\hline - Total cholesterol & 5.0 & 6.4 \\
- Triglycerides & 17.8 & 23.7 \\
- LDL-cholesterol & 7.8 & 8.2 \\
- HDL-cholesterol & 7.1 & 7.5 \\
- ApoA-I & 7.1 & \\
- ApoB & 6.4 & \\
\hline
\end{tabular}

Abbreviations: apoA-I, apolipoprotein A-I; apoB, apolipoprotein-B; CVP, coefficient of physiologic variation; HDL, high-density lipoprotein; LDL, low-density lipoprotein.

a more individualized subsequent mention. The clinician must integrate laboratory data and its interpretation in a more global appreciation of metabolism and individual medical and family history, which entails forecast the potential importance of variation factors in presence that may or may not affect the significance.

That is why, before moving forward to a therapeutic proposal or adjustment, we should take into account the mean variation profile of plasma lipid and lipoproteins levels and not accept an isolated value. Additionally, a dyslipidaemia diagnosis should be repeated once or more than once, at baseline and confirmed, at least, after 4 weeks, in order to validate or deny the lipid profile under evaluation.

\subsection{Screening of a dyslipidaemia for the evaluation of total CV risk}

Dyslipidaemia, as we have already stated, has a causal role in ASCVD and, consequently, in CV risk. CV risk should be regarded as the likelihood of a person developing a fatal or non fatal ASCV event over a defined period of time. Despite the crucial importance of a dyslipidaemia - namely hypercholesterolaemia - in ASCVD, this pathology is usually the result of the interaction of several risk factors. Thereby, all current guidelines on the prevention and management of CVD emphasize the importance of assessing and adjusting the supervision and treatment to total CV risk: "the higher the risk, the more intense the action should be" [4].

In Portugal, the use of SCORE risk chart is recommended to evaluate total CV risk [17]. With the application of a risk chart such as SCORE we aim to identify the 10-year cumulative absolute risk of a first fatal ASCV event (e.g. heart attack, stroke or other occlusive arterial disease, including sudden cardiac death) in apparently healthy people with no recognized CVD. Individuals with documented clinical CV event, such as acute coronary syndrome (ACS) or stroke, type 1 or type 2 diabetes (T2DM), very high individual risk factors (e.g. familial hypercholesterolaemia or blood pressure $\geq 180 / 110 \mathrm{mmHg}$ ), and chronic kidney disease (CKD) - kidney structure or function abnormal, with glomerular fraction rate (GFR) $<60 \mathrm{~mL} / \mathrm{min} / 1.73 \mathrm{~m}^{2}$, for more than 3 months - are routinely at very high or high total CV risk, and no risk estimation is required $[4,5,17]$. For all other healthy individuals, the use of SCORE risk estimation is recommended.

Obviously, since SCORE risk chart only appraises the first fatal CV event probability, the risk of total fatal and non-fatal ASCV event is higher. The SCORE data points to total $\mathrm{CV}$ event risk being approximately 3 times higher than the risk of fatal CVD in men and 4 times higher in women but, to some extent, lower in elderly. In older patients the likelihood of having a first fatal CV event is naturally higher $[4,5]$.

Screening for dyslipidaemia is indicated in patients with clinical CVD (secondary prevention), in clinical conditions correlated with 
Table 3

Who to screen for dyslipidaemia in adults at risk (adapted from Anderson et al., 2016).

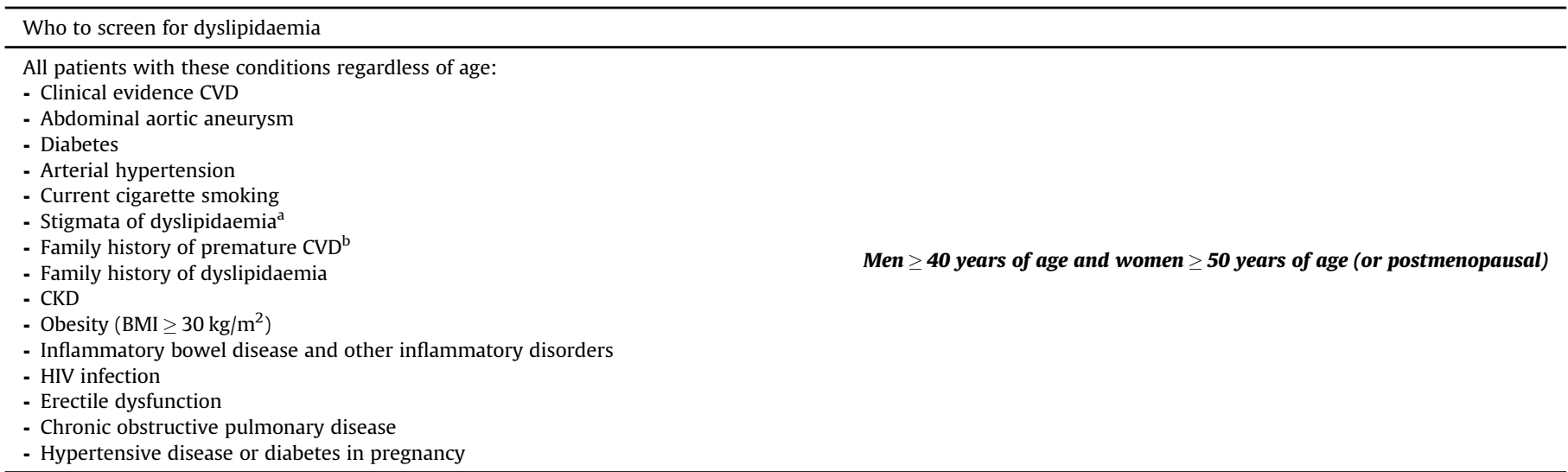

Notes: a. Arcus cornea, xanthelasma or xanthoma; b. *Men younger than 55 years and women younger than 65 years of age in first-degree relative.

Abbreviations: BMI, body mass index; CVD, cardiovascular disease; CKD, chronic kidney disease; HIV, human of immunodeficiency virus.

an increased risk for CVD (primary prevention), and in many different situations in which risk factor selection and evaluation should be considered $[4,5,18]$ (Table 3). Examples of these eventual circumstances are autoimmune chronic inflammatory conditions (e.g. rheumatoid arthritis, systemic lupus erythematous and psoriasis), women with former history of diabetes or hypertensive diseases of pregnancy - which includes preeclampsia and pregnancy-induced hypertension -, men with erectile dysfunction, patients with CKD, and individuals with clinical manifestations or family history consistent with genetic dyslipidaemias. It is also fundamental to screen for dyslipidaemia in patients with obesity, metabolic syndrome (MetS) and/or diabetes [nonetheless, patients with $\mathrm{T} 2 \mathrm{DM}<40$ ages, with a short duration of therapy, with no others risk factors or target organ damages, with a LDL-C $<100 \mathrm{mg}$ / $\mathrm{dL}(2.6 \mathrm{mmol} / \mathrm{L})$ may not need lipid-lowering intervention, and HIV-infected with or without (high active) antiretroviral treatment $[4,5]$.

It is essential to emphasize the deliberation of screening for dyslipidaemias in all adults (men $\geq 40$ years and in women $>50$ years of age or postmenopausal), specially in the presence of other "classic" CV risk factors (e.g. arterial hypertension and current cigarette smoking) $[4,5,16]$. It is also recommended to screen offspring of patients with severe dyslipidaemia and family members of patients with premature CVD [4,5,16].

We suggest that a baseline lipid evaluation must include the estimation of TC, TGs, HDL-C, LDL-C - calculated with the Friedewald formula or evaluated by a direct method -, and nHDL-C. There are other lipid (and non-lipid) markers which may complement the data provided by the standard lipid profile and, eventually, support the therapeutic decision-making. If available, and in specific clinical circumstances, apoB and $\mathrm{LP}(\mathrm{a})$ can also be estimated. The suggestion to evaluate other plasma lipid ratio - like apoB/apoA-I or HDLC/LDL-C - is less consistent and should deserve individual consideration.

\subsection{Total and low-density lipoprotein cholesterol}

Cholesterol accounts for almost all of the sterol in plasma, and subsists as a mixture, quite stable among normal individuals, of unesterified (30\%-40\%) and esterified (60\%-70\%) forms. TC and lipoprotein-cholesterol concentrations are usually expressed without distinguishing these 2 (esterified and unesterified) fractions. The differentiation of these forms is only recommended when it is important to quantify the fatty acid moiety to cholesteryl ester mass or the cholesterol/cholesteryl ester mass ratio [14].
TC is used to estimate total CV risk in SCORE model. We wish to underline - as it has been emphasized by the 2016 Guidelines of dyslipidaemias [4] - that the majority of risk estimation systems and mostly all drug trials are based on TC and LDL-C, and most of the data obtained with other, sometimes logical, lipid markers (including apoB, nHDL-C and ratios) resulted from post hoc analyses. However, in some clinical situations TC can be misleading, such as in women with high levels of HDL-C (and hence with also higher CT levels) and in patients with HTG and obesity, MetS or diabetes with low HDL-C levels. These and other potential clinical situations justify that the determination of LDL-C and HDL-C are also considered in the adequate $\mathrm{CV}$ risk evaluation.

LDL is the major cholesterol carrying lipoprotein in plasma. LDL contains apoB-100 as its major protein, and is cleared from the plasma with a residence time of approximately 2.0 days. LDL is further divided into large buoyant LDL (lb-LDL; density $1.019-1.044 \mathrm{~g} / \mathrm{mL}$ ) and small dense LDL (sd-LDL; density $1.044-1.063 \mathrm{~g} / \mathrm{mL}$ ). The apoB-100 in the LDL particle has a plasma residence time of approximately 1.5 days, but when large buoyant LDL is converted to sd-LDL, its apoB-100 moiety is cleared slower, with a plasma residence time of almost 3 days [19].

Multiple randomized clinical trials (RCTs) support the unequivocal evidence that the decrease of TC or LDL-C - at least in patients with high and moderate $\mathrm{CV}$ risk - is associated with important reductions in CV events and mortality. Every $1.0 \mathrm{mmol} / \mathrm{L}$ $(38.6 \mathrm{mg} / \mathrm{dL}$ ) reduction in LDL-C is linked to a subsequent $20-25 \%$ reduction in CVD mortality and non-fatal MI, 23\% reduction of major coronary events, $17 \%$ reduction in stroke and $10 \%$ proportional reduction in all-cause mortality $[20,21]$. The risk reduction was similar in all subgroups examined and the benefits were significant within the first year and continued to rise in subsequent years.

Several methods have been used to measure LDL-C however, these techniques are out of the scope of this paper [14,18,22,23]. In clinical practice, LDL-C is either estimated by the Friedewald formula or directly measured. The former is a calculation determined by plasma TGs, TC, and HDL-C. In fasting plasma samples, LDL contains the cholesterol not present in HDL or VLDL. Thus, because VLDL carries most plasma TGs, VLDL-cholesterol (VLDL-C) concentration is estimated from the ratio of TGs to cholesterol in VLDL, and LDL-C can be determined by the Friedewald equation in which concentrations are expressed in $\mathrm{mg} / \mathrm{dL}$, and VLDL-C is represented by [plasma TGs]/5: 
$[$ LDL-cholesterol $]=([$ total cholesterol $]-[$ HDL-cholesterol $])-$ [plasma TGs]/5

When the results are expressed in $\mathrm{mmol} / \mathrm{L}$, VLDL-cholesterol is estimated by [plasma TGs]/2.175. It has been stated that the factor [plasma TGs]/2.825 gives a precise estimate of VLDL-C (14), and that this relation is equivalent to [plasma TGs/6.5], when concentrations are expressed in $\mathrm{mg} / \mathrm{dL}$. The ratio that provides the best accurate estimation of cholesterol in VLDL is under discussion, since this relation varies among populations and is affected by the laboratorial method used to measure TGs. Calculated LDL-C does not add additional expense beyond the 3 core measurements (TGs, TC, and HDL-C), but it requires a fasting sample. By contrast, direct measurement of LDL-C does not require fasting samples, but does comprise extra expenses.

The Friedewald formula has significant limitations [14,24], that arise mostly from several assumptions on which the method is based. First, from an analytical point of view, the inaccuracy of the Friedewald equation derives from the inaccuracies and imprecision of TC, HDL-C, and TGs measurements, namely the significant limitations in measuring both HDL-C (determination of HDL-C is particularly challenging and even a small analytical error can contribute to misclassification) and TGs. Second, the formula assumes that all plasma TGs are carried in VLDL and that the TG/ cholesterol ratio of VLDL is invariable. Neither assumption is entirely true. The calculation is not valid for samples having TGs $>400 \mathrm{mg} / \mathrm{dL}$, for patients with type III hyperlipoproteinaemia or chylomicronaemia, or nonfasting specimens. The method is unsuitable for nonfasting samples that contain chylomicrons (CMs) or samples that contain $\beta$-VLDL. Compared with VLDL, in nonfasting conditions, the ratio of TGs to cholesterol in CMs is much higher and can, therefore, underestimate LDL-C. Similarly, in the presence of $\beta$-VLDL, the ratio is much lower and overestimates LDL-C determination. Even in CMs-free samples, the ratio of VLDL-C to TGs changes as TGs levels increase. The calculation is not adequate for high TGs concentrations: errors in LDL-C become perceptible with TGs $>2.26 \mathrm{mmol} / \mathrm{L}$ ( $200 \mathrm{mg} / \mathrm{dL}$ ) and become disappointingly significant with TGs $>4.52 \mathrm{mmol} / \mathrm{L}(400 \mathrm{mg} / \mathrm{dL})$. In patient with diabetes, the Friedewald formula appeared to underestimate LDL-C by $8-10 \%$, often with a poor correlation between the Friedewald equation, ultracentrifugation or a direct LDL-C assay [24]. Under these conditions it would be better to consider the determination of nHDL-C as an alternative.

Since the Friedewald formula was first published in 1972, several investigators have tried to improve its accuracy to estimate LDL-C [25]. Recently, a group of researchers [26], though recognizing that the implementation of a factor of 5 to every individual patient could be challenging, given the variance in the TG:VLDL-C ratio across the range of TGs and nHDL-C levels, proposed a new novel LDL-C estimate derived as (nHDL-C) - (TGs/adjustable factor) $(\mathrm{mg} / \mathrm{dL})$, where the adjustable factor was established as the strataspecific median TG:VLDL-C ratio. Apparently, this new estimation method provided a best estimate of LDL-C, particularly in patients with LDL-C $\leq 70 \mathrm{mg} / \mathrm{dL}$ in the presence of high TGs levels (see below)

Another topic to consider is non-LDL lipoproteins. Normally, LDL contributes to most part of the measured cholesterol, and IDL and $\mathrm{Lp}(\mathrm{a})$ contribute only with a few $\mathrm{mg} / \mathrm{dL}$ each. However, in some hyperlipidaemia patients, these lipoproteins can contribute significantly to cholesterol measurements [27]. Currently, aggressive LDL-C lowering strategies are recommended to prevent ASCVD in high-risk populations and guidelines recommend, at least, a 50\% reduction in very high-risk patients if baseline LDL-C concentrations are between 70 and $135 \mathrm{mg} / \mathrm{dl}(1.8-3.54 \mathrm{mmol} / \mathrm{L})$. In a recent paper in this type of patients, calculated LDL-C $<30 \mathrm{mg} / \mathrm{dL}$
( $0.8 \mathrm{mmol} / \mathrm{L}$ ) must not be reported because of significant deviation from the gold standard measured LDL-C results, and concern was recommended when using Friedewald formula in patients with calculated LDL-C $<70 \mathrm{mg} / \mathrm{dL}(1.8 \mathrm{mmol} / \mathrm{L})$ to make treatment decisions [28]. Similarly, another group of investigators [29] showed that the equation tends to underestimate LDL-C in high-risk patients, and to classify an LDL-C as $>70 \mathrm{mg} / \mathrm{dl}$, especially with TGs $>150 \mathrm{mg} / \mathrm{dL}$, in spite of directly measured levels of LDL-C being higher than $70 \mathrm{mg} / \mathrm{dL}$.

Apparently, direct LDL-C methods are useful when TGs are elevated, because they are less subject to interference by TGs even at relatively high concentrations $(600 \mathrm{mg} / \mathrm{dL})$. Another potential advantage is the convenience of measuring LDL-C in nonfasting individuals, although some experts have recommended against it [14]. However, in HTG these methods can also be less reliable (with inconsistent results and discrepancies between the different available techniques), with over- or underestimation of the LDL-C (and also HDL-C) [4]. Again, the use of nHDL-C or apoB - when available - can overcome some of these contradictions. Specialists in clinical chemistry, in their laboratories, should ultimately be responsible for defining the best method to use when determining LDL-C concentration and the technique used must be clearly stated by the laboratory providing the information.

\subsection{High-density lipoprotein cholesterol, triglycerides and non- high-density lipoprotein cholesterol}

Low HDL-C is also included in many risk estimation tools; in the SCORE database, HDL-C has a shy although useful effect in redefining risk estimation, in both genders and in all age groups (especially in elderly) and is particularly important at risk levels immediately under the $5 \%$ threshold for intensive risk modification $[4,5]$. Epidemiological studies suggest that an HDL-C $<45 \mathrm{mg} / \mathrm{dL}$ $(<1.2 \mathrm{mmol} / \mathrm{L})$ in women and $<40 \mathrm{mg} / \mathrm{dL}(<1.0 \mathrm{mmol} / \mathrm{L})$ in men can be assumed as an additional marker for increased CV risk. However, Mendelian randomization studies have consistently jeopardized the role of HDL-C as a protective factor in atherosclerosis and CVD [30], which has resulted in assessing the significance and the relevance of dysfunctional HDL in atherogenesis [31]. From the laboratorial standpoint, most of the available assays for direct measurement provide high quality, but we must remember that HTG can interfere in the validity of the measurements.

TGs are assessed by accurate enzymatic laboratorial techniques and these methods provide a link to the epidemiological database for CVD risk. The association of TGs with CV risk is weaker than for hypercholesterolaemia, but is clearly a significant independent CV risk factor. This relationship is sustained by recent genetic data [30], and non-fasting TGs may carry information on remnant lipoproteins and remnant cholesterol. High TGs are commonly connected with low HDL-C and high levels of sd-LDL (e.g. diabetic dyslipidaemia). Non-fasting TGs can be applied in general screening and $\mathrm{CV}$ risk evaluation. From this point of view, fasting TGs $>\sim 150 \mathrm{mg} /$ $\mathrm{dL}(>1.7 \mathrm{mmol} / \mathrm{L})$ continue to be regarded as a marker of increased $\mathrm{CV}$ risk (but should not considered as a target levels for therapy).

The TGs measurement should not include free glycerol, but many clinical laboratories do not correct for free glycerol. In the majority of the patients' samples, the input of free glycerol to TGs is small and, therefore, it does not have to impact the clinical decision and the calculation of LDL-C. Free glycerol concentration may be increased in the presence of strenuous exercise, liver disease, diabetes, hemodialysis, parenteral nutrition, intravenous medications containing glycerol, and stress. In patients with hyperglycerolaemia the levels of TGs are falsely very high [4,24].

Non-HDL-cholesterol is an estimation of all plasma atherogenic lipoproteins [VLDL, VLDL remnants, intermediate-density 
lipoproteins (IDL), LDL, and Lp(a)], calculated from TC minus HDL-C, and is associated with apoB levels. With a strong predictive CV risk power, nHDL-C is simple to estimate - involving no additional analyses -, does not require fasting conditions, and is a better risk indicator than LDL-C [32]. In dyslipidaemia management, nHDL-C should be used as a secondary target when LDL-C goal is achieved.

Even though some researchers [33] suggested that in Mediterranean population the burden of atherogenic particles should be taken into consideration in patients with mild hypertriglyceridaemia and different cut-off values have been proposed (100 and $130 \mathrm{mg} / \mathrm{dL}$ for LDL-C goals of 70 and $100 \mathrm{mg} / \mathrm{dL}$, respectively), the goal for nHDL-C must remain the LDL-C goal plus $30 \mathrm{mg} /$ $\mathrm{dL}(0.77 \mathrm{mmol} / \mathrm{L})$, as recommended by European guidelines $[4,5]$.

\subsection{Apolipoproteins}

Studies have indicated that apoA-I and apoB may be better discriminators of CVD risk than lipid or lipoprotein determinations. ApoA-I, being the major apolipoprotein of HDL (which also has apoA-II), has a production rate of approximately $12 \mathrm{mg} / \mathrm{kg} /$ day and has a residence time of approximately 4 days, while apoB is the major apolipoprotein of the atherogenic lipoproteins: VLDL, IDL, and LDL, it stands to reason apoB/apoA-I ratio is one of the strong risk markers [5], but with limited evidence to be considered as a treatment goal. Apolipoproteins are usually measured by immunoassay, such as immunonephelometry, the analytical performance is good but more expensive than the other common lipid parameters; it does not require fasting samples and it is not modified with markedly elevated TGs levels.

\subsubsection{Apolipoprotein $B$}

Each apoB-lipoprotein has only one apoB molecule. Therefore, serum concentration of apoB can be considered as a good estimate for the number of these particles in plasma and has been claimed as a stronger CV risk indicator [34]. ApoB is not included in algorithms to estimate global $\mathrm{CV}$ risk and has not been evaluated as a primary target in clinical trials. Nevertheless, many post-hoc analysis and meta-analysis of RCTs suggest that apoB must be also being seen as a potential secondary treatment target, when available [4,35]. However, albeit the reasonable targets for apoB can be obtained from epidemiological studies - for instance, as mentioned above, the apoB values proposed for Mediterranean individuals were 70 and $80 \mathrm{mg} / \mathrm{dL}$ for very-high or high CV risk cluster [33] - there is still a large difference between the proposed apoB cut-off values.

\subsubsection{Apolipoprotein A-I}

In contrast with apoB, apoA-I - the major protein in $\mathrm{HDL}$ - does not necessarily evaluate the number of HDL particles (each HDL particle can bear one to five apoA-I molecules), but nevertheless we can consider that plasma apoA-I levels $<120 \mathrm{mg} / \mathrm{dL}$ for men and $<140 \mathrm{mg} / \mathrm{dL}$ for women correspond roughly to what is believed as low HDL-C levels.

\subsubsection{Apolipoprotein C-III}

Apolipoprotein C-III (apoC-III), primarily present in CMs and VLDL, was first identified as a regulator of TGRLs in the circulation, an inhibitor of lipoprotein lipase (LPL) activity, and a key regulator of plasma TGRLs concentration. ApoC-III also facilitates hepatic VLDL assembly and secretion, contributes to the atherogenicity of LDL and HDL particles - the reason to be recognized as a possible important new CV risk factor -, and can also modulate the endothelial function and inflammation [36]. Loss of function mutations is associated with low TGs levels and a significant decline in CV risk [4]. Standardized clinical immunoassays for the measurements of apoC-III concentrations are not available; also, due to the complexity of different apoC-III multiple glycoforms, distributed in lipoprotein fractions, the development of novel techniques with high sensitivity and specificity is critical [36]. Even though apoC-III may become a new potential therapeutic target, its role in clinical practice is unknown and its routine evaluation is not recommended.

\subsection{Other lipid markers: lipoprotein (a) and small-dense low density lipoprotein}

Lp(a) has been perceived as an independent CV risk marker and genetic data confirm that it is causal in ASCVD and in aortic stenosis $[4,37,38]$. Plasma levels of $\mathrm{LP}(\mathrm{a})$ are predominantly determined by genetic factors (>90\%), via variation in the apolipoprotein(a) gene (gene $L P A$ ), and are very stable throughout life thus reiterating that evaluations are not required for risk assessment.

Lp(a) has common properties with LDL - with an apolipoprotein (a) [apo(a)] in its structure, homologous to plasminogen - and also a similar density to LDL (but it migrates on VLDL electrophoretic region). When $\mathrm{Lp}(\mathrm{a})$ plasma levels are very high, it may be necessary to correct LDL-C for the contribution of $\mathrm{Lp}(\mathrm{a})$-cholesterol. To estimate the contribution of $\mathrm{Lp}(\mathrm{a})$-cholesterol to the measured LDL$C$ value, where the values are given in $\mathrm{mg} / \mathrm{dL}$, the following relationship has been used: $\operatorname{Lp}(\mathrm{a})$-cholesterol $=0.3 \times[\mathrm{Lp}(\mathrm{a})$ mass], hence $[\mathrm{LDL}$-cholesterol $]=([$ total cholesterol $]-[\mathrm{HDL}$-cholesterol $])-$ [plasma TGs]/5 - (0.3 x [Lp(a) mass]). Currently, routine measurement of $\operatorname{Lp}(\mathrm{a})$ is not recommended, however it must be evaluated in specific patients (Table 4). The CV risk is significant when $\mathrm{Lp}(\mathrm{a})>50 \mathrm{mg} / \mathrm{dL}$, and in patients at risk with high levels of $\mathrm{Lp}(\mathrm{a})$ it is reasonable to intensify the treatment of modifiable CV risk factors, namely LDL-C (with intensive lipid-lowering therapy).

Lipoproteins consist of heterogeneous subclasses of particles with varying density, size, electrophoretic mobility, relative lipidprotein proportions, and binding affinity. LDL particles are fractionated according to size and density into lb-LDL (diameter $\geq 25.5 \mathrm{~nm}$ ) and sd-LDL (diameter $<25.5 \mathrm{~nm}$ ). Decreased size and increased density of LDL have been associated with increased CV risk. Elevated concentrations of sd-LDL correlate with high TGs and low HDL-C levels in plasma (the so-called "atherogenic lipoprotein phenotype"). Metabolic studies showed that sd-LDL particles derive from the delipidation of larger atherogenic VLDL and large LDL and from direct de novo hepatic production [39]. However, the causal relationship of sd-LDL - as well as diverse subclasses of HDL - with ASCVD is uncertain and reason for debate. The existing data suggest that sd-LDL is more atherogenic than lb-LDL, because it remains longer in plasma, and its protein and lipid constituents are more liable to modification and to be picked up by scavenger receptors.

Several methods have been developed to assess sd-LDL particles (density gradient ultracentrifugation, gradient gel electrophoresis, tube gel electrophoresis, and nuclear magnetic resonance). These processes can be expensive, time-consuming, and technically demanding, rendering them too difficult for routine clinical practice or screening. The measurement of sd-LDL, looked upon as an emergent risk factor, is not currently recommended for CV risk estimation [4]. Recently, a group of investigators developed a formula to estimate sd-LDL-C using classical lipid profile from routine clinical laboratories [40]. The calculated LDL-C was obtained with the Friedewald formula (after excluding liver or renal disease). By stepwise regression analysis, $\mathrm{nHDL}-\mathrm{C}$ and calculated and direct LDL-C were identified, as significant variables. The obtained regression equation in $\mathrm{mg} / \mathrm{dL}$ was: sd-LDL-C $=0.580$ (nHDLC) +0.407 (direct LDL-C) -0.719 (calculated LDL-C) - 12.05. However, the study did not evaluate the proposed equation in some specific individuals with dyslipidaemias (e.g. CVD, CKD, diabetes or MetS, and type III hyperlipoproteinaemia). Future studies are 
Table 4

Indications for $\mathrm{Lp}(\mathrm{a})$ screening (adapted from Catapano et al., 2016; Nordestgaard et al., 2010; and Kostner et al., 2013).

Individuals who should be considered for $\mathrm{Lp}(\mathrm{a})$ screening ...

- Premature CVD

- Familial hypercholesterolaemia

- Family history of premature CVD and/or elevated Lp(a)

- Recurrent CVD despite optimal lipid-lowering treatment

- $\geq 5 \%$ in 10 -year risk of fatal CVD according to SCORE

- Hemodialysis patients and patients with $\mathrm{CKD}(?)$

- Intermediate risk group (3-5\%) in 10-year risk of fatal CVD according to SCORE(?)

Abbreviations: CVD, cardiovascular disease; CKD, chronic kidney disease; Lp(a), lipoprotein (a); SCORE, Systematic Coronary Risk Evaluation.

required to corroborate the equation and its potential application in all populations.

\section{Fasting or non-fasting}

Traditionally, blood samples for lipid measurements are obtained in fasting conditions. Ideally, patients should fast for 10-12 h before the blood sample collection. CMs are usually present in postprandial plasma, depending on the type and amount of food ingested, and can increase the plasma TGs concentration; LDL-C and HDL-C also decline transiently in the postprandial period, consequence, at least in part, of the CETP (cholesterol ester transfer protein)-mediated compositional changes during the metabolism of CMs; these lipoproteins are almost completely cleared within $6-9 \mathrm{~h}$ (their presence after a $12-\mathrm{h}$ fast is abnormal).

Generally, TC and HDL-C, as well as nHDL-C can be measured in non-fasting conditions. When TGs and LDL-C are measured, fasting becomes a requirement since the postprandial presence of $\mathrm{CMs}$ and compositional changes in LDL can lead to the underestimation of LDL-C. These assumptions, however, have been the subject of strong controversy [41-43]. Fasting and non-fasting lipid blood tests show comparable results for TC, LDL-C and HDL-C, with a very small increase $( \pm 20 \%)$ in TGs.

The response to dietary fat and postprandial lipaemia (PPL) is a polygenic phenomenon. In contrast to changes seen in TGs subsequent to a oral fat load [44], after a normal meal TGs increase only $\sim 18-27 \mathrm{mg} / \mathrm{dL}(0.2-0.3 \mathrm{mmol} / \mathrm{L})$, usually peaking $4 \mathrm{~h}$ during postprandial period, and LDL-C levels reduce, by an average of $8-11 \mathrm{mg} / \mathrm{dL}(0.1-0.2 \mathrm{mmol} / \mathrm{L})$ or $10 \%$, either because of hemodilution or exchange of cholesterol on LDL by TG, or as a result of the application of the Friedewald formula. TC, HDL-C, nHDL-C, and apoB 100 do not vary substantially after meals [18].

Besides, in CV risk estimation, fasting and non-fasting lipid levels have similar predictive strength, suggesting that non-fasting lipid levels can be applied in screening and risk estimation [4,45] (with a possible exception: patients with diabetes that, in nonfasting samples, can have lower LDL-C and underestimation in CV risk). Non-fasting condition may slightly lower LDL-C due to liberal intake of fluids and, therefore, lead to a potential minor misclassification of CV risk or an error in the initiation or titration of lipidlowering medication particularly, in diabetic patients. It is wise to recall that with non-fasting plasma TGs $>440 \mathrm{mg} / \mathrm{dL}$ ( $>5 \mathrm{mmol} / \mathrm{L}$ ) it is vital to repeat the lipid profile in the fasting state and that laboratory reports should flag abnormal values based on desirable concentration cut-points (see below) [45]. It is also important to remember that the complete characterization of severe dyslipidaemias and the follow-up of patients with HTG do not mitigate fasting conditions [4].

Non-fasting and fasting measurements of the lipid profile must be regarded as complementary and not mutually exclusive [45]
(Table 5). Although we spent most of the day in non-fasting condition, fasting lipid profile is still the standard in clinical practice. Overall, a 12-h fasting period is still considered appropriate when lipoprotein measurements are used in CV risk screening and estimation and in the characterization of dyslipidaemias before treatment $[4,16]$.

\section{Treatment targets and laboratory reports}

The most important purpose of CVD risk assessment is (1) to persuade individuals without treatable risk factors and low CV risk to maintain healthy lifestyles, (2) to advise individuals with treatable CV risk factors or unhealthy behaviours to modify their attitudes and to treat and manage the modifiable risk factors, and (3) to identify subjects who would most probably benefit from pharmacotherapy and concomitant lifestyle interventions.

Ideally, the decision-making thresholds and treatment goals derive from RCTs and demand to randomly allocate subjects to different lipid goals levels. There is a continuous relationship between TC and LDL-C reduction and reduction in CVD risk. Nonetheless, most available evidence in different treatment goals is based on observational studies and post hoc analyses of RCTs (and meta-regression analyses) randomly distributing different treatment strategies instead of treatment goals and, therefore, the 2016 recommendations in dyslipidaemias and CV prevention [4,5] derived from consensus based in all the available best evidence, namely large-scale epidemiological data and lipid-lowering RCTs. The clinical benefits with lipid-lowering therapy are related to the LDL-C reduction achieved and are not specific to statin therapy. The intervention strategies rely on total CV risk evaluated and baseline LDL-C level: the higher the CVD risk, the greater the clinical benefits obtained with lipid-lowering therapy are and the higher the initial LDL-C, the larger the absolute risk reduction (despite the relative risk reduction remains constant, regardless the baseline LDL-C values).

Total CV risk reduction should be individualized and more explicit treatment goals should be identified [4]. It is also important not to disregard the considerable individual variability in LDL-C response to dietary and drugs treatments (with significant implications in terms of CVD risk reduction and events) [46,47]. The use of lipid treatment goals can facilitate effective communication between patients and clinicians - providing an interpretable means to communicate the progress obtained in meeting treatment objectives -, maximizing long-term adherence to the treatment plan and increasing the clinical benefits of lipid-lowering drug treatment in primary and secondary ASCVD prevention.

LDL-C is recommended as the primary target for treatment, but TC may be a treatment target if other lipid analyses are not available. nHDL-C and/or apoB, when available, should be considered as secondary treatment targets. HDL-C and apoB/apoA-I and nHDL-C/ HDL-C are not recommended as treatment targets [4]. In some specific situations or patients, achieving the threshold LDL-C goal is not adequate or desirable, and, in some cases, the clinician may even decide to treat LDL-C values well below the goals. Total CV risk management and treatment must be individualized. There is evidence suggesting that lowering LDL-C beyond goals can be safe and associated with fewer ASCVD events [21,48,49].

As we already suggested, in compliance with most of the major international guidelines and with Portuguese standards of GCP from DGS [17] (Fig. 1), we strongly recommend the clinician to estimate total CV risk to assess the lipid and lipoprotein profile, to delineate a sustained therapeutic strategy and the corresponding treatment target, by introducing a shared decision-making and a relevant clinician-patient risk discussion (taking into account the potential treatment benefits, the risk of adverse events, and patient 
Table 5

Use of non-fasting and fasting assessment of plasma lipid profile (from Nordestgaard et al., 2016).

\begin{tabular}{|c|c|}
\hline Patients for non-fasting lipid profile testing & Patients for fasting lipid profile testing \\
\hline $\begin{array}{l}\text { - Initial lipid profile testing in any patient } \\
\text { - For CV risk assessment } \\
\text { - Patients admitted with ACS }{ }^{\mathrm{a}} \\
\text { - In children } \\
\text { - If preferred by the patient } \\
\text { - In diabetic patients }{ }^{\mathrm{b}} \text { (due to hypoglycaemia) } \\
\text { - In the elderly } \\
\text { - Patients on stable drug therapy }\end{array}$ & $\begin{array}{l}\text { - Non-fasting TGs }>440 \mathrm{mg} / \mathrm{dL}(>5 \mathrm{mmol} / \mathrm{L} \text { ) } \\
\text { - Known HTG followed in lipid clinic } \\
\text { - Recovering from hypertriglyceridaemic pancreatitis } \\
\text { - Starting drugs that cause severe HTG } \\
\text { Additional laboratory tests requested that require fasting or morning samples } \\
\text { (e.g. fasting glucosec, therapeutic drug monitoring) }\end{array}$ \\
\hline
\end{tabular}

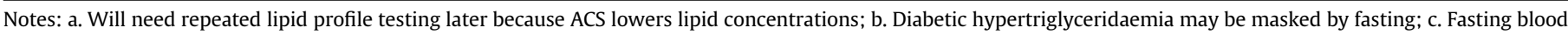

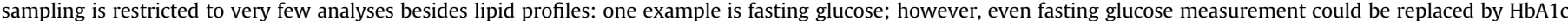
without the need to fast.

Abbreviations: ACS, acute coronary syndrome; CV, cardiovascular; TGs, triglycerides.

preferences before making a final decision on treatment).

With these assumptions, we must take into consideration the following levels of total CV risk, supported by the existence of certain comorbidities and/or in the SCORE risk calculation (settled on by gender, age, systolic blood pressure, TC and smoking habits) $[4,5]$ :

- The low-risk level affects the individuals with a 10-year $\mathrm{SCORE}<1 \%$. Most of these individuals must keep lifestyle intervention but do not require pharmacologic therapy, except those with LDL-C $\geq 190 \mathrm{mg} / \mathrm{dL}$ ( $\geq 5.0 \mathrm{mmol} / \mathrm{L}$ ), usually with a genetic dyslipidaemia such as familial hypercholesterolemia, which have to be included in high-risk group.

- The moderate-risk level includes a significant proportion of the Portuguese population (in VIVA study [50]) and covers individuals with a SCORE risk $\geq 1 \%$ and $<5 \%$ for 10 -year risk of fatal CVD. Please note that for subjects with intermediate risk, many other markers and factors (qualifiers), such as metabolic factors (increased apoB, LP(a), or TGs), inflammatory markers (highsensitivity C-reactive protein [hs-CRP]), albuminuria, or subclinical atherosclerosis indicators (coronary artery calcium score $[C A C]>400$ Angstrom, ankle-brachial index $[A B I]<0.9$ or 1.40 , pulse wave velocity $\geq 10 \mathrm{~m} / \mathrm{s}$, or the occurrence of plaques on carotid ultrasonography) can improve CV risk reclassification.
- The high-risk group includes individuals with a SCORE risk $\geq 5 \%$ and $<10 \%$ for 10 -year risk of fatal CVD, and all the subjects with a markedly elevated single risk factor, namely TC $>310 \mathrm{mg} / \mathrm{dL}$ ( $>8 \mathrm{mmol} / \mathrm{L}$, as in familial hypercholesterolemia) or blood pressure $\geq 180 / 110 \mathrm{mmHg}$, a large number of diabetics (some young individuals with type 1 diabetes may have a low or moderate CV risk), and individuals with moderate CKD (GFR 30-59 mL/min $/ 1.73 \mathrm{~m}^{2}$ ).

- Finally, the very high-risk group embraces all the patients with clinical or unequivocal evident CVD on imaging [including previous MI, ACS, coronary revascularization [percutaneous coronary intervention or coronary artery bypass graft surgery] and other arterial revascularization procedures, stroke and TIA, and peripheral arterial disease [PAD]). This particular CV risk group also comprises diabetics with target organ damage (e.g. proteinuria) or with a major risk factor (e.g. smoking, hypertension or dyslipidaemia), patients with severe CKD (GFR $<30 \mathrm{~mL} / \mathrm{min} / 1.73 \mathrm{~m}^{2}$ ), and all individuals with a calculated SCORE $\geq 10 \%$ for 10 -year risk of fatal CVD.

Thus, these diverse CV risk groups are associated with distinct treatment approaches and different target lipid values $[4,5,15]$ :

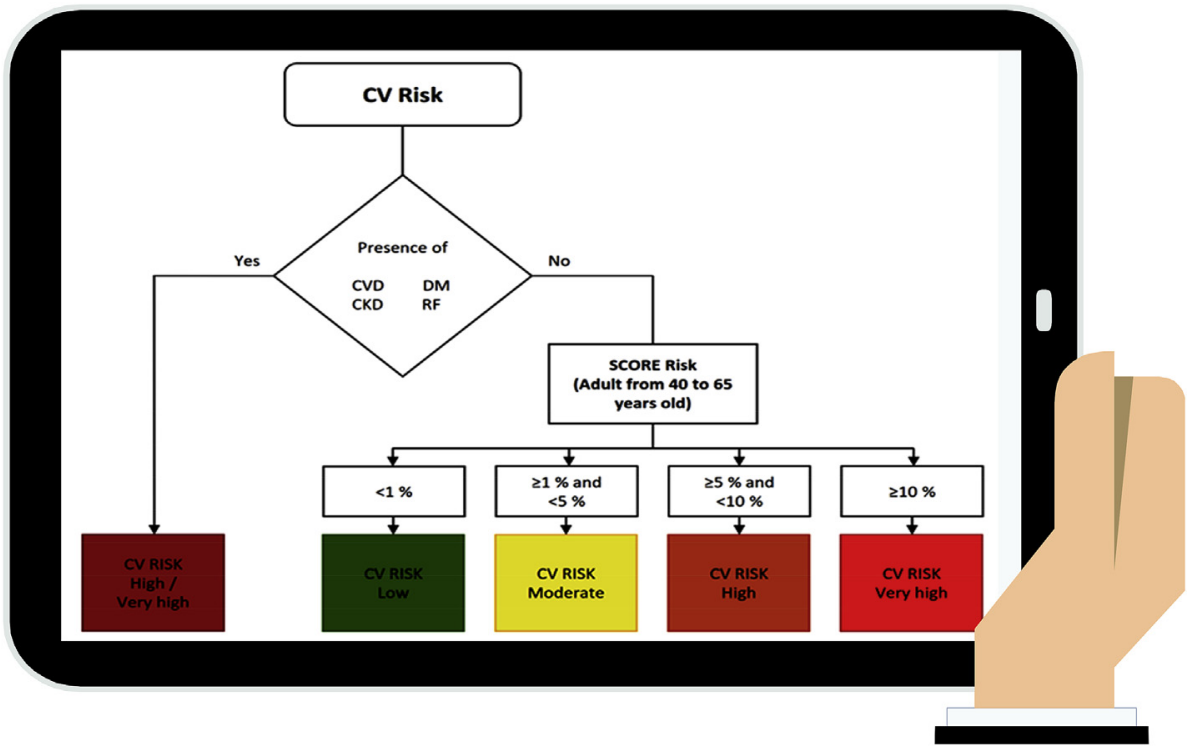

Fig. 1. Clinical algorithm in the assessment of total $\mathrm{CV}$ risk. 
- Lifestyle advice and a LDL-C goal of $<115 \mathrm{mg} / \mathrm{dL}(<3.0 \mathrm{nmol} / \mathrm{L})$ should be proposed to individuals with low- to moderate-risk.

- Patients at high CV risk are qualified for intensive lifestyle advice and are usual candidates for drug treatment. In these patients, the $\mathrm{LDL}-\mathrm{C}$ goal is $<100 \mathrm{mg} / \mathrm{dL}(<2.6 \mathrm{mmol} / \mathrm{L})$, or a reduction of at least $50 \%$ if the baseline LDL-C is between 100 and $200 \mathrm{mg} / \mathrm{dL}$ (2.6 and $5.2 \mathrm{mmol} / \mathrm{L}$ ).

- In very high-risk individuals it is crucial to start drug treatment, and an LDL-C goal of $<70 \mathrm{mg} / \mathrm{dL}(<1.8 \mathrm{mmol} / \mathrm{L})$ or a decrease of at least $50 \%$ if the baseline LDL-C is between 70 and $135 \mathrm{mg} / \mathrm{dL}$ ( 1.8 and $3.5 \mathrm{mmol} / \mathrm{L}$ ) is recommended. Please note that in individuals $>60$ years of age, the calculated SCORE threshold risk should not be so strictly deducted, because their age-specific risk is normally around these levels, even when other CV risk factor levels are 'normal'. Hasty initiation of drug treatments of all elderly individuals with SCORE risk $>10 \%$ should be discouraged.

Along with the necessary standardization of clinical laboratory tests, the methods used in the determination of lipid profile should be stated and the laboratory report must be harmonized. In cases of direct determination of a lipid parameter, the laboratory equipment and the variation coefficient associated with the chosen method should also be specified.

Harmonization means ensuring that the results of different laboratories, using different clinical laboratory tests, at different times, to measure the same substance, are equivalent within clinically meaningful limits [51]. If the laboratory tests used in the guidelines and in GCP orientations are not harmonized, tests results do not always support the clinical directions, which can mislead patients and physicians. Instead or together with the reference values - that, in most cases, originate from the information supplied by the manufacturer in the package insert - we propose that the report of lipid test results includes specific information on LDL$\mathrm{C}$ target values, according to the different $\mathrm{CV}$ risk groups.

It could be fair to argue that this type of "personalized report" of desirable target values is difficult to put into practice because, usually, the laboratory professional has no information on the clinical conditions and risk factors of the patient. To avoid alarming the patient, with this inclusion in a specific risk group before being seen by the patient's physician, and to overcome this clinical information problem, the laboratory report should have lipid target values, according to the different CV risk groups, with a clear indication that these are decision-making values rather than reference values.

We believe that, with this approach, make easy the lipid profile interpretation and get better the patient's interest in its own CVD risk and LDL-C target attainment. We include an example of an eventual instruction for the lipid reference values report (Fig. 2). From a conceptual point of view, results of lipid parameters are considered abnormal if they exceed the age- and sex-specific reference interval ( $\approx 2.5$ th to 97.5 th percentiles). We propose that laboratory reports should flag nonstandard values based on desirable concentration cut-points, defined by guidelines and consensus statements $[4,5,15,16,45]$, to ensure that this value must receive specific attention.

Because of its prognostic connotations, some rarer conditions, with extreme abnormal lipid values, deserve further attention in laboratory reports: TGs $>880 \mathrm{mg} / \mathrm{dL}(10 \mathrm{mmol} / \mathrm{L})$, because of the risk for acute pancreatitis, LDL-C $>190 \mathrm{mg} / \mathrm{dL}(5 \mathrm{mmol} / \mathrm{L})$ or $\mathrm{TC}>240 \mathrm{mg} / \mathrm{dL}[6.2 \mathrm{mmol} / \mathrm{L}]$ in adults or $>155 \mathrm{mg} / \mathrm{dL}(4 \mathrm{mmol} / \mathrm{L})$ in children, because of their potential relationship with familial hypercholesterolemia, and $\mathrm{Lp}(\mathrm{a})>150 \mathrm{mg} / \mathrm{dL}$, because it is associated with a very high risk of MI and aortic valve stenosis [45].

\subsection{Frequency of testing for dyslipidaemia}

The importance of screening for lipid disorders (in adults, but also in childhood) is the early identification of dyslipidaemia and the estimation of the individual level of CV risk, the motivation for dietary and lifestyle interventions, and, if appropriate, the introduction of pharmacological treatment (or its potential intensification) to reduce the risk and severity of CVD. In the large majority of individuals, lipid disorders are clinically silent and isolated selective screening fail to identify a substantial number of individuals in CV risk and dyslipidaemia.

However, the determination of lipid values should be repeated once or more than once at baseline, with an interval of few weeks. The diagnosis of dyslipidaemia should always be confirmed by a subsequent laboratorial evaluation of lipid profile, carried out with a minimum interval of 4 weeks, prior to the beginning of any pharmacological therapy [16]. The frequency of testing depends on the individual's CV risk profile; if it is clearly under a threshold for drug intervention, then we suggest repeating lipid measurements every five years or every three years in patients close to the threshold for treatment (based on total CV risk or and LDL-C goal). A few studies suggest that a three- to four years interval of monitoring lipid levels is perhaps the minimum necessary to understand true trends in cholesterol [52], depending on the CV risk at baseline [53].

Please note that, nevertheless, acute stress and metabolic serious disturbances are often related to variations, more or less obvious, in the lipid profile. This is, perhaps, one of the reasons why we advise the need for a short resting period (10-15 min) in a calm and relaxing atmosphere before collecting the blood sample for laboratory evaluation. The relationship between hospitalization and the reduction of LDL-C and HDL-C is a paradigmatic example of the effect of stress on the lipid profile. In hospitalized patients, the lipid profile should not be evaluated routinely, unless there is a specific clinical indication (e.g. unknown personal history of dyslipidaemia and the need to establish total CV risk and, in that case, it must be done in the first hours of the hospitalization, in the occurrence of non-alcoholic steatohepatitis or pancreatitis) [16]. Acute MI is also associated with decreased TC, LDL-C and apoB (depending on the baseline value prior to the event), a reduction of HDL-C (and apoA-I) and a progressive increase of TGs. These changes are detected within the first $24-48 \mathrm{~h}$, and may extend for 6-8 weeks (up to 3 months, in extreme cases). Analogous variations occur with stroke (especially thromboembolic), acute febrile, infectious or inflammatory processes or post-surgical [54].

Lifestyle modifications are a crucial component for ASCVD risk reduction. Adherence to these steps should be regularly and continuously assessed. After 4-12 weeks of the initiation of drug treatment - namely with a statin - a second fasting lipid panel (TC, TG, HDL-C and, whenever possible, LDL-C) should be performed (55), in order to evaluate the response to the treatment (both the obtained percentage of LDL-C reduction from the baseline and the absolute on-treatment LDL-C value) and to assess the patient's adherence to treatment (with the potential support of the indication and the adjustment of the lipid drug management to the lipid target goals). Afterwards, assessments should be performed every 3 months, until the therapeutic lipid goals are not achieved, and every 12 months after that, as clinically indicated [16,55].

When a modification is made to LDL-C lowering therapy (e.g. any intensification of lifestyle interventions, titration in statin therapy, or adding of non-statin therapies), we recommended a new lipid panel, again 4-12 weeks of the treatment adjustment, and, later, to resume the regimen already enunciated (every 3-12 months) [16,55]. 


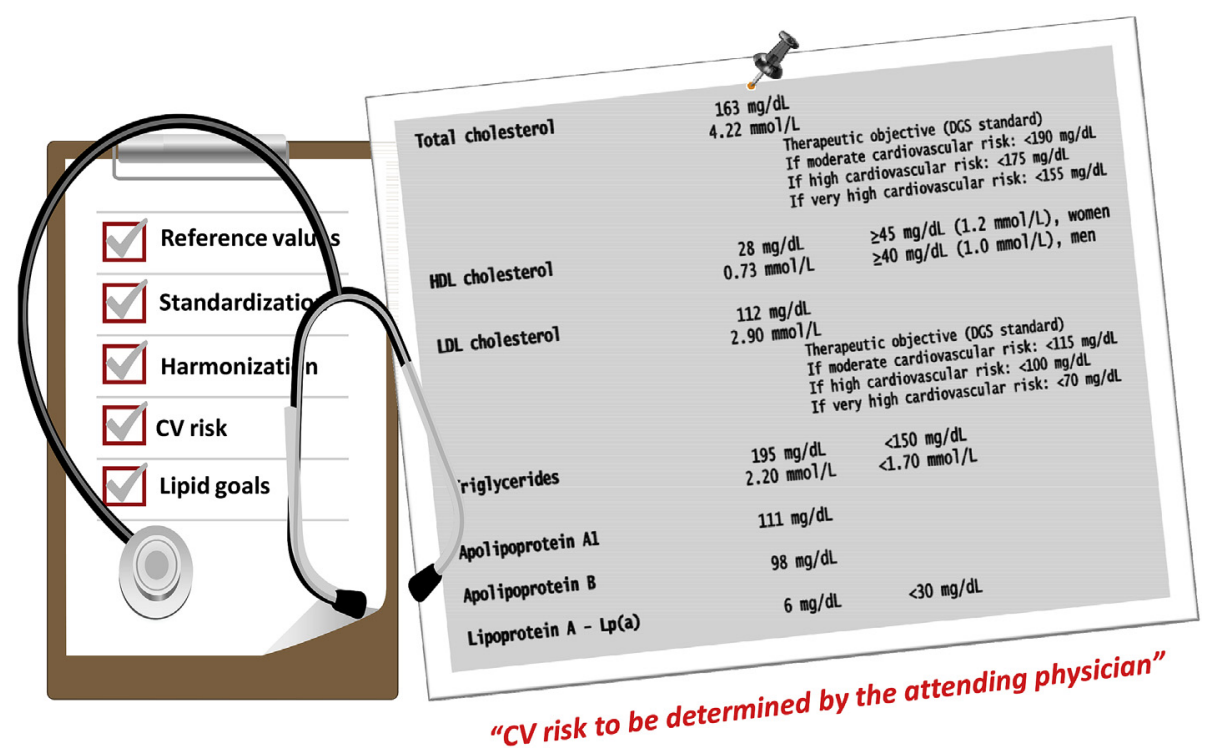

Fig. 2. A possible example of a lipid values report.

\section{Synopsis (authors' main recommendations) and conclusion}

This consensus document aims to provide clinicians with practical guidance for the harmonization and standardization of clinical laboratory lipid tests, focusing on the more recent dyslipidaemia management guidelines.

We recommend an adequate screening, diagnosis, monitoring and treatment of dyslipidaemias, as a crucial part for CVD prevention in clinical practice. To evaluate total CV risk, we support the SCORE risk chart (adjusted for low-risk European countries, including Portugal, and, ideally, taking into account HDL-C) and the determination of first fatal ASCV risk event at 10 years, in apparently healthy people with no recognized CVD. People with clinical CV event, type 1 or T2DM, very high of individual risk factors and CKD are at very high or high total CV risk and no risk estimation are required.

Screening for dyslipidaemia is indicated in all adults (men $\geq 40$ years and in women $\geq 50$ years of age or postmenopausal), mainly in the presence of other "classic" CV risk factors, in patients with clinical CVD (secondary prevention) or with clinical conditions associated with increased CV risk (primary prevention), namely in patients with obesity, metabolic syndrome (MetS) and/or diabetes, in HIV-infected patients, and in people with a family history of severe dyslipidaemia and premature CVD. The baseline fasting lipid evaluation must include TC, TGs, HDL-C, LDL-C - calculated with the Friedewald formula or evaluated by a direct method -, and nHDL-C. When available, apoB and Lp(a) can also be assessed.

Total CV risk reduction should be individualized and treatment goals should be identified. LDL-C is the primary treatment target, and TC could be accepted if other lipid parameters are not available. nHDL-C and/or apoB should be regarded as secondary treatment targets. HDL-C and apoB/apoA-I are not recommended as treatment targets. We strongly recommend that the treatment lipid goals take into consideration the total CV risk.

In low- and moderate-risk individuals a LDL-C goal of $<115 \mathrm{mg} /$ $\mathrm{dL}(<3.0 \mathrm{nmol} / \mathrm{L})$ should be considered. In patients in high CV risk, the LDL-C goal is $<100 \mathrm{mg} / \mathrm{dL}(<2.6 \mathrm{mmol} / \mathrm{L})$, or a reduction of at least $50 \%$ if the baseline LDL-C is between 100 and $200 \mathrm{mg} / \mathrm{dL}(2.6$ and $5.2 \mathrm{mmol} / \mathrm{L}$ ). In very high-risk patients the LDL-C goal $<70 \mathrm{mg} /$ $\mathrm{dL}(<1.8 \mathrm{mmol} / \mathrm{L})$ or a decrease of at least $50 \%$ if the baseline LDL-C is between 70 and $135 \mathrm{mg} / \mathrm{dL}$ ( 1.8 and $3.5 \mathrm{mmol} / \mathrm{L}$ ) is recommended.

We strongly reinforce the importance of lipid test reports including specific information on LDL-C target values, according the different CV risk groups, perhaps complemented by the statement "your individual total CV risk to be determined by your attending physician". We also propose that laboratory reports should flag nonstandard values based on desirable concentration cut-points, defined by guidelines and consensus statements (Table 6). The diagnosis of dyslipidaemia should always be confirmed by a second laboratorial lipid profile, carried out with a minimum interval of 4 weeks, prior to the beginning of any pharmacological therapy [16]. The frequency of testing depends on the individual's CV risk profile.

Four to 12 weeks after initiating lipid lowering drug treatment, a second fasting lipid panel should be performed. Afterwards, assessments should be performed every 3 months, until the therapeutic lipid goals are not achieved, and, later, every 12 months, as clinically indicated. When a modification is made to LDL-C lowering therapy we recommended a new lipid panel, 4-12 weeks of the treatment adjustment, and, later, to resume the regimen already mentioned.

Table 6

Abnormal plasma lipid, lipoprotein, and apolipoprotein concentrations values, in fasting condition, which should be flagged in laboratory reports (adapted from Nordestgaard et al., 2016).

\begin{tabular}{|c|c|c|}
\hline Abnormal concentrations & $\mathrm{mg} / \mathrm{dL}^{\mathrm{a}}$ & $\mathrm{mmol} / \mathrm{L}$ \\
\hline $\begin{array}{l}\text { - Triglycerides } \\
\text { - Total cholesterol } \\
\text { - LDL cholesterol } \\
\text { - Non-HDL cholesterol } \\
\text { - Lipoprotein }(\mathrm{a})^{\mathrm{b}} \\
\text { - Apolipoprotein B } \\
\text { - HDL cholesterol } \\
\text { - Apolipoprotein A-I }\end{array}$ & $\begin{array}{l}\geq 150 \\
\geq 190 \\
\geq 115 \\
\geq 145 \\
\geq 50 \\
\geq 100 \\
\leq 40 \\
\leq 125\end{array}$ & $\begin{array}{l}\geq 1.7 \\
\geq 5 \\
\geq 3 \\
\geq 3.8\end{array}$ \\
\hline
\end{tabular}

a Values in $\mathrm{mmol} / \mathrm{L}$ were converted to $\mathrm{mg} / \mathrm{dL}$ by multiplication with 38.6 for cholesterol and by 88 for triglycerides, followed by rounding to nearest $5 \mathrm{mg} / \mathrm{dL}$; for total cholesterol, we used $5 \mathrm{mmol} / \mathrm{L}$ and $190 \mathrm{mg} / \mathrm{dL}$, as these are the two desirable concentration cut-point used in guidelines.

b There is no complete consensus on which cut-point value that should be used for lipoprotein(a).

c Sex-specific cut-points are, normally, used for HDL cholesterol. 
ASCVD (and its pleiotropic clinical manifestations) are preventable and its consequences greatly not inevitable. In 2014, the circulatory system diseases (cerebrovascular and ischaemic heart diseases) remain one of the main underlying causes of death in Portugal [1]. We want to promote the best healthcare of individuals - of both gender and all ages - with or at risk of ASCVD. We are aware that $\mathrm{CV}$ effective prevention is, frequently, overlooked in our daily practice. $\mathrm{CV}$ prevention emerged as an ethical state. It is important to recognize the CV risk, enhance the importance of laboratory reports and to identify clinical situations that deserve our careful intervention.

\section{Funding}

No external funding was used in the preparation of this manuscript.

\section{Conflicts of interest}

PMS has received lecture honoraria or consulting fees from Bayer, JABA-Recordati, Merck Sharp and Dohme Portugal, Kowa Pharmaceuticals, Novartis, Daiichi Sankyo, Amgen, SanofiRegeneron, and Tecnimede. JSD has received lecture honoraria or consulting fees from Novo-Nordisk, Merck Sharp and Dohme Portugal, Sanofi-Regeneron, Novartis Oncology, BoheringherIngleheim, and Tecnimede. VG has received honorary from Astra Zeneca, Merck Sharp Dohme Portugal, Bial, Jaba-Recordatti, and Amgen. Other members have no conflicts of interest to declare.

\section{Acknowledgment}

The consensus panel wishes to express its gratitude to Anabela Farrica and Diogo Ribeiro from Eurotrials, Scientific Consultants, S.A., whose assistance was invaluable in preparing the first draft of this document.

\section{References}

[1] Instituto Nacional de Estatística. Estatísticas da Saúde 2015. Lisboa - Portugal: INE, I.P; 2017.

[2] Saúde Direção-Geral de. Portugal: doenças cérebro-cardiovasculares em números. Programa Nacional para as Doenças Cérebro-Cardiovasculares. DGS, fevereiro de 2016; 2015.

[3] Townsend N, Wilson L, Bhatnagar P, Wickramasinghe K, Rayner M, et al. Cardiovascular disease in Europe: epidemiological update 2016. Eur Heart J 2016;37(42):3232-45.

[4] Catapano AL, Graham I, De Backer G, Wiklund O, Chapman MJ, et al. 2016 ESC/ EAS guidelines for the management of dyslipidaemias: the task force for the management of dyslipidaemias of the European society of cardiology (ESC) and European atherosclerosis society (EAS) developed with the special contribution of the European association for cardiovascular prevention \& rehabilitation (EACPR). Atherosclerosis 2016;253:281-344. https://doi.org/ 10.1016/j.atherosclerosis.2016.08.018.

[5] Piepoli MF, Hoes AW, Agewall S, Albus C, Brotons C, et al. P 2016 European guidelines on cardiovascular disease prevention in clinical practice: the sixth joint task force of the European society of cardiology and other societies on cardiovascular disease prevention in clinical practice (constituted by representatives of 10 societies and by invited experts) developed with the special contribution of the European association for cardiovascular prevention \& rehabilitation (EACPR). Atherosclerosis 2016;252:207-74. https://doi.org 10.1016/j.atherosclerosis.2016.05.037.

[6] Borén J, Williams KJ. The central role of arterial retention of cholesterol-rich apolipoprotein-B-containing lipoproteins in the pathogenesis of atherosclerosis: a triumph of simplicity. Curr Opin Lipidol 2016;27(5):473-83. https:// doi.org/10.1097/MOL.0000000000000330.

[7] Nordestgaard BG. Triglyceride-rich lipoproteins and atherosclerotic cardiovascular disease: new insights from epidemiology, genetics, and biology. Circ Res 2016;118(4):547-63. https://doi.org/10.1161/CIRCRESAHA.115.306249.

[8] Costa J, Oliveira E, David C, Borges M, Gouveia M, et al. Prevalence of hypercholesterolemia in Portugal and Europe: the same reality? Rev Port Cardio 2003;22(7-8):967-74.

[9] Costa J, Borges M, Oliveira E, Gouveia M, Carneiro AV. Incidence and prevalence of hypercholesterolemia in Portugal: a systematic review. Part I. Rev
Port Cardiol 2003;22(4):569-77.

[10] Costa J, Borges M, Oliveira E, Gouveia M, Carneiro AV. Incidence and prevalence of hypercholesterolemia in Portugal: a systemic review. Part II. Rev Port Cardiol 2003;22(5):683-702.

[11] Costa J, Borges M, Oliveira E, Gouveia M, Carneiro AV. Incidence and prevalence of hypercholesterolemia in Portugal: a systematic review. Part III. Rev Port Cardiol 2003;22(6):829-36.

[12] Fundação Portuguesa de Cardiologia. Perfil lipídico da população portuguesa. FPC, Instituto de Alimentação Becel; 2001.

[13] Gouveia M, Borges M, Augusto M, Caldeira D, Alarcão J, et al. Cost and burden of hypercholesterolemia in Portugal. Value Health 2014;17(7):A339.

[14] Chen X, Zhou L, Hussain MM. Lipids and dyslipoproteinemia. In: McPherson RA, Pincus MR, editors. Henry's clinical diagnosis and management by laboratory methods. 23th edition. St. Louis: Elsevier; 2017. p. $221-43$.

[15] 23. Norma $n^{\circ}$ 019/2011 de 28/09/2011 atualizada a 11/05/2017: abordagem terapêutica das dislipidemias no adulto. Accessed in August of 2017: file:///C:/ Users/Pedro/Downloads/i023641.pdf.

[16] Direção-Geral de Saúde. Norma no 066/2011 de 30/12/2011 atualizada a 26/ 02/2015: prescrição de exames laboratoriais para a avaliação das dislipidemias no adulto. Accessed in August of 2017: file:///C:/Users/Pedro/ Downloads/i021112.pdf.

[17] 24. Direção-Geral de Saúde. Norma no 005/2013 de 19/03/2013 atualizada a 21/05/2015: avaliação do risco cardiovascular SCORE (Systematic Coronary Risk Evaluation). Accessed in August of 2017: file:///C:/Users/Pedro/ Downloads/i020960.pdf.

[18] Anderson TJ, Gregoire J, Pearson GJ, Barry AR, Couture P, et al. 2016 Canadian Cardiovascular Society guidelines for the management of dyslipidemia for the prevention of cardiovascular disease in the adult. Can J Cardiol 2016;32(11): 1263-82. https://doi.org/10.1016/j.cjca.2016.07.510.

[19] Schaefer EJ, Tsunoda F, Diffenderfer M, Polisecki E, Thai N, et al. In: De Groot LJ, Beck-Peccoz P, Chrousos G, Dungan K, Grossman A, Hershman JM, Koch C, McLachlan R, New M, Rebar R, Singer F, Vinik A, Weickert MO, editors. The measurement of lipids, lipoproteins, apolipoproteins, fatty acids, and sterols, and next generation sequencing for the diagnosis and treatment of lipid disorders. South Dartmouth (MA): MDText.com, Inc; 2000-2016 Mar 29. Endotext [Internet].

[20] Cholesterol Treatment Trialists' (CTT) Collaboration, Baigent C, Blackwell L, Emberson J, Holland LE, et al. Efficacy and safety of more intensive lowering of LDL cholesterol: a meta-analysis of data from 170,000 participants in 26 randomised trials. Lancet 2010;376(9753):1670-81. https://doi.org/10.1016/ S0140-6736(10)61350-5.

[21] Collins R, Reith C, Emberson J, Armitage J, Baigent C, et al. Interpretation of the evidence for the efficacy and safety of statin therapy. Lancet 2016;388(10059):2532-61. https://doi.org/10.1016/S0140-6736(16)31357-5.

[22] Nauck M, Warnick GR, Rifai N. Methods for measurement of LDL-cholesterol: a critical assessment of direct measurement by homogeneous assays versus calculation. Clin Chem 2002;48(2):236-54.

[23] Leiviskä J. Laboratory diagnostics of dyslipidemia. From cholesterol to apolipoproteins [academic dissertation]. Helsinki: National Institute for Health and Welfare; 2013.

[24] Contois JH, Warnick GR, Sniderman AD. Reliability of low-density lipoprotein cholesterol, non-high-density lipoprotein cholesterol, and apolipoprotein B measurement. J Clin Lipidol 2011;5(4):264-72. https://doi.org/10.1016/ j.jacl.2011.05.004.

[25] Dansethakul P, Thapanathamchai L, Saichanma S, Worachartcheewan A, Pidetcha P. Determining a new formula for calculating low-density lipoprotein cholesterol: data mining approach. EXCLI J 2015;14:478-83. https:// doi.org/10.17179/excli2015-162.

[26] Martin SS, Blaha MJ, Elshazly MB, Toth PP, Kwiterovich PO, et al. Comparison of a novel method vs. the Friedewald equation for estimating low-density lipoprotein cholesterol levels from the standard lipid profile. JAMA 2013;310(19):2061-8. https://doi.org/10.1001/jama.2013.280532.

[27] Ellis KL, Pang J, Chan DC, Hooper AJ, Bell DA, et al. Familial combined hyperlipidemia and hyperlipoprotein(a) as phenotypic mimics of familial hypercholesterolemia: frequencies, associations and predictions. J Clin Lipidol 2016;10(6):1329-37. https://doi.org/10.1016/j.jacl.2016.08.011. e3.

[28] Meeusen JW, Snozek CL, Baumann NA, Jaffe AS, Saenger AK. Reliability of calculated low-density lipoprotein cholesterol. Am J Cardiol 2015;116(4): 538-40. https://doi.org/10.1016/j.amjcard.2015.05.013.

[29] Martin SS, Blaha MJ, Elshazly MB, Brinton EA, Toth PP, et al. Friedewaldestimated versus directly measured low-density lipoprotein cholesterol and treatment implications. J Am Coll Cardiol 2013;62(8):732-9. https://doi.org/ 10.1016/j.jacc.2013.01.079.

[30] Jansen H, Samani NJ, Schunkert H. Mendelian randomization studies in coronary artery disease. Eur Heart J 2014;35(29):1917-24. https://doi.org/ 10.1093/eurheartj/ehu208.

[31] Rosenson RS, Brewer Jr HB, Ansell BJ, Barter P, Chapman MJ, et al. Dysfunctional HDL and atherosclerotic cardiovascular disease. Nat Rev Cardiol 2016;13(1):48-60. https://doi.org/10.1038/nrcardio.2015.124.

[32] Puri R, Nissen SE, Shao M, Elshazly MB, Kataoka Y, et al. Non-HDL cholesterol and triglycerides: implications for coronary atheroma progression and clinical events. Arterioscler Thromb Vasc Biol 2016:36(11):2220-8.

[33] Martinez-Hervas S, Real JT, Priego MA, Carratalá A, Sniderman AD, et al. Establishing cut-off values for apolipoprotein B and non-HDL-C according to 
LDL-C values in a South European population. Int J Clin Pract 2013;67(1): 81-8. https://doi.org/10.1111/j.1742-1241.2012.02998.x.

[34] Pencina MJ, D'Agostino RB, Zdrojewski T, Williams K, Thanassoulis G, et al Apolipoprotein B improves risk assessment of future coronary heart disease in the Framingham Heart Study beyond LDL-C and non-HDL-C. Eur J Prev Cardiol 2015;22(10):1321-7. https://doi.org/10.1177/2047487315569411.

[35] Thanassoulis G, Williams K, Ye K, Brook R, Couture P, et al. Relations of change in plasma levels of LDL-C, non-HDL-C and apoB with risk reduction from statin therapy: a meta-analysis of randomized trials. J Am Heart Assoc 2014;3(2). https://doi.org/10.1161/JAHA.113.000759. e000759.

[36] Taskinen MR, Borén J. Why is apolipoprotein CIII emerging as a novel therapeutic target to reduce the burden of cardiovascular disease? Curr Atherosclerosis Rep 2016;18(10):59. https://doi.org/10.1007/s11883-016-0614-1.

[37] Nordestgaard BG, Chapman MJ, Ray K, Borén J, Andreotti F, et al. European Atherosclerosis Society Consensus Panel. Lipoprotein(a) as a cardiovascular risk factor: current status. Eur Heart J 2010;31(23):2844-53. https://doi.org/ 10.1093/eurheartj/ehq386.

[38] Kostner KM, März W, Kostner GM. When should we measure lipoprotein (a)? Eur Heart J 2013;34(42):3268-76. https://doi.org/10.1093/eurheartj/eht053.

[39] Diffenderfer MR, Schaefer EJ. The composition and metabolism of large and small LDL. Curr Opin Lipidol 2014;25(3):221-6. https://doi.org/10.1097/ MOL.0000000000000067.

[40] Srisawasdi P, Chaloeysup S, Teerajetgul Y, Pocathikorn A, Sukasem C, et al Estimation of plasma small dense LDL cholesterol from classic lipid measures. Am J Clin Pathol 2011;136(1):20-9. https://doi.org/10.1309/ AJCPLHJBGG9L3ILS.

[41] Driver SL, Martin SS, Gluckman TJ, Clary JM, Blumenthal RS, et al. Fasting or nonfasting lipid measurements: it depends on the question. J Am Coll Cardiol 2016;67(10):1227-34. https://doi.org/10.1016/j.jacc.2015.12.047.

[42] Mora S. Nonfasting for routine lipid testing: from evidence to action. JAMA Intern Med 2016;176(7):1005-6. https://doi.org/10.1001/ jamainternmed.2016.1979.

[43] Rifai N, Young IS, Nordestgaard BG, Wierzbicki AS, Vesper H, et al. Nonfasting sample for the determination of routine lipid profile: is it an idea whose time has come? Clin Chem 2016;62(3):428-35. https://doi.org/10.1373/ clinchem.2015.247866.

[44] Kolovou GD, Mikhailidis DP, Nordestgaard BG, Bilianou H, Panotopoulos G. Definition of postprandial lipaemia. Curr Vasc Pharmacol 2011;9(3):292-301.

[45] Nordestgaard BG, Langsted A, Mora S, Kolovou G, Baum H, et al. European Atherosclerosis Society (EAS) and the European Federation of Clinical Chemistry and Laboratory Medicine (EFLM) joint consensus initiative. Fasting is not routinely required for determination of a lipid profile: clinical and laboratory implications including flagging at desirable concentration cut-points - a joint consensus statement from the European Atherosclerosis Society and European Federation of Clinical Chemistry and Laboratory Medicine. Eur Heart 2016;37(25):1944-58. https://doi.org/10.1093/eurheartj/ehw152.

[46] Boekholdt SM, Hovingh GK, Mora S, Arsenault BJ, Amarenco P, et al. Very low levels of atherogenic lipoproteins and the risk for cardiovascular events: meta-analysis of statin trials. J Am Coll Cardiol 2014;64(5):485-94. https:// doi.org/10.1016/j.jacc.2014.02.615.

[47] Karlson BW, Wiklund O, Palmer MK, Nicholls SJ, Lundman P, et al. Variability of low-density lipoprotein cholesterol response with different doses of atorvastatin, rosuvastatin, and simvastatin: results from VOYAGER. Eur Heart J Cardiovasc Pharmacother 2016;2(4):212-7. https://doi.org/10.1093/ehjcvp/ pvw006.

[48] Hsia J, MacFadyen JG, Monyak J, Ridker PM. Cardiovascular event reduction and adverse events among subjects attaining low-density lipoprotein cholesterol $<50 \mathrm{mg} / \mathrm{dl}$ with rosuvastatin. The JUPITER trial (Justification for the Use of Statins in Prevention: an Intervention Trial Evaluating Rosuvastatin). J Am Coll Cardiol 2011;57(16):1666-75. https://doi.org/10.1016 j.jacc.2010.09.082.

[49] Cannon CP, Blazing MA, Giugliano RP, McCagg A, White JA, et al. IMPROVE-IT Investigators. Ezetimibe added to statin therapy after acute coronary syndromes. N Engl J Med 2015;372(25):2387-97. https://doi.org/10.1056/ NEJMoa1410489.

[50] Um em cada quatro adultos corre risco de morrer de enfarte. Jornal Público; 23 de abril de 2012. Accessed in August of 2017, www.publico.pt/2012/04/23 sociedade/noticia/um-em-cada-quatro-adultos-corre-risco-de-morrer-deenfarte-1543207.

[51] American Association for Clinical Chemistry. The need to harmonize clinical laboratory test results. A White Paper of the American Association for Clinica Chemistry; July 2015.

[52] Glasziou PP, Irwig L, Heritier S, Simes RJ, Tonkin A. LIPID Study Investigators. Monitoring cholesterol levels: measurement error or true change? Ann Intern Med 2008;148(9):656-61.

[53] Bell KJ, Hayen A, Irwig L, Takahashi O, Ohde S, et al. When to remeasure cardiovascular risk in untreated people at low and intermediate risk: observational study. BMJ 2013;346:f1895. https://doi.org/10.1136/bmj.f1895.

[54] da Silva PM. In: Vale, Vale, editors. Temas cardiológicos: dislipidemias. Edição. Sociedade Portuguesa de Aterosclerose; 2002.

[55] Lloyd-Jones DM, Morris PB, Ballantyne CM, Birtcher KK, Daly Jr DD, et al. A 2016 ACC expert consensus decision pathway on the role of non-statin therapies for LDL-cholesterol lowering in the management of atherosclerotic cardiovascular disease risk: a report of the American College of Cardiology Task Force on Clinical Expert Consensus Documents. J Am Coll Cardiol 2016;68(1):92-125. https://doi.org/10.1016/j.jacc.2016.03.519. 